\title{
“COMUNIDADE GERATIVA" E "COMUNIDADE DE AFETO": PROPOSTAS CONCEITUAIS PARA ESTUDOS COMPARATIVOS DE COMUNICAÇÃO COMUNITÁRIA
}

\author{
"GENERATIVE COMMUNITY” AND "COMMUNITY OF AFFECT": \\ CONCEPTUAL PROPOSALS FOR COMMUNITY MEDIA COMPARATIVE \\ STUDIES \\ "COMUNIDAD GENERADORA" Y "COMUNIDAD DE \\ AFECTO/COMUNIDAD AFFECTIVE": UNA PROPUESTA DE CONCEPTOS \\ PARA ESTUDIOS COMPARATIVOS DE MEDIOS COMUNITARIOS"
}

Raquel Paiva

Professora, Universidade Federal do Rio de Janeiro paivaraquel@hotmail.com

João Paulo Malerba

Doutorando, Universidade Federal do Rio de Janeiro joaopaulorj@yahoo.com.br

Leonardo Custódio Doutorando, Universidade de Tampere (Finlândia) leonardo.custodio@uta.fi

\section{Resumo}

O objetivo deste trabalho é propor o uso dos conceitos de "comunidade gerativa" e "comunidade de afeto" para estudos comparativos de comunicação comunitária em contextos sociais distintos. Usando os países BRICS (Brasil, Rússia, Índia, China e África do Sul) como pano de fundo e o Brasil como estudo de caso, identificamos como abordagens à comunicação comunitária em estudos comparativos recentes são tipicamente burocráticas e não permitem análises empíricas aprofundadas sobre o tema. Em seguida, definimos "comunidade gerativa" e "comunidade de afeto." Por fim, apresentamos exemplos brasileiros para demonstrar como estes conceitos podem gerar estudos amplos sobre motivações, práticas e consequências das ações comunicacionais contra-hegemônicas de atores da sociedade civil.

Palavras-chave: Comunicação comunitária. Comunidade de afeto. Comunidade gerativa. BRICS.

Esta obra está licenciada sob uma Licença Creative Commons 


\begin{abstract}
This article aims at proposing the use of the concepts "generative community" and "community of affect" for comparative studies of community media in distinct social contexts. By using the BRICS countries (Brazil, Russia, India, China and South Africa) as a backdrop and Brazil as a case study, we identify how contemporary comparative approaches to community media are typically bureaucratic and do not allow more in-depth empirical analysis of the theme. Then, we define "generative community" and "community of affect." At last, we present Brazilian examples to demonstrate how these concepts can generate broader studies about the motivations, practices and consequences of the counter-hegemonic communication activities of civil society actors.
\end{abstract}

Keywords: Community media. Community of affect. Generative community. BRICS.

\title{
Resumen
}

El presente artículo tiene como objetivo proponer el uso de los conceptos "comunidad generadora" y "comunidad de afecto" en estudios comparativos de medios comunitarios en diferentes contextos sociales. Con los llamados BRICS (Brasil, Rusia, India, China y Sudáfrica) como telón de fondo y Brasil como el estudio de caso a analizar, identificaremos cómo los enfoques comparativos sobre medios comunitarios de la actualidad suelen ser burocráticos/rígidos e impiden un análisis empírico de esta temática más profundo. Además, trataremos de definir "comunidad generadora" y "comunidad de afecto". Por último, a través del ejemplo de Brasil demostraremos cómo estos conceptos pueden ser usados como base para estudios más amplios sobre las motivaciones, prácticas y consecuencias de la comunicación anti-hegemónica de los actores de la sociedad civil.

Palabras clave: Medios comunitarios. Comunidad de afecto. Comunidad generadora. BRICS.

\section{INTRODUÇÃO: O DESAFIO DA DIVERSIDADE DE INICIATIVAS CONTRA- HEGEMÔNICAS NOS BRICS}

Em sua edição mais recente e atualizada do livro "L'avenir d'une revolte" (KRISTEVA, 2012), a filósofa e psicanalista Julia Kristeva traça um perfil da necessidade da revolta, da rebelião, do rebelar-se. E é exatamente desta sua concepção, deste espírito - sem o qual, como ela argumenta, não resta nada mais para globalização que os cálculos das taxas de crescimento e das probabilidades genéticas - que nos valemos para defender a necessidade da atuação e das pesquisas em torno das práticas de comunicação contra-hegemônicas, comunitárias, populares, alternativas, cidadãs, dentre tantas nomenclaturas que denotam a 
utilização éticopolítica dos meios por uma dada comunidade - seja ela territorial, de interesse ou etnolinguística - com intuitos de mobilização e transformação social.

A temática se inscreve para nós como a única possibilidade de reversão do modelo dominante de produção midiática atual, marcada pelo intenso fluxo informacional, incompatibilidade com o quotidiano das populações e pautada pela espetacularização e indução ao consumo desenfreado. A revolta é caracterizada por Kristeva como a única possibilidade de futuro e é esta a ênfase, relativa à potencialidade da recriação, que imprimimos esta nossa preocupação quando inserimos a questão da comunicação comunitária no projeto que pretende estudar os sistemas de mídia dos países integrantes dos BRICS ${ }^{1}$ (Brasil, Rússia, Índia, China e África do Sul).

Com o intuito de aprofundar o conhecimento sobre os países BRICS a partir do campo da comunicação, a Universidade de Tampere (Finlândia) lançou o projeto de pesquisa "Sistemas Midiáticos em Fluxo: O desafio dos países BRICS."² O projeto $(2012$ - 2016) é coordenado pelo Professor Emérito Kaarle Nordenstreng. Para evitar um estudo comparativo internacional sob uma perspectiva eurocêntrica, o "Projeto BRICS" tem parceiros locais que participam ativa e criticamente da elaboração de metas e do refinamento teórico e metodológico da pesquisa. No Brasil, a Universidade Federal do Rio de Janeiro (UFRJ) é a principal parceira através do Laboratório de Estudos em Comunicação Comunitária (LECC) ${ }^{3}$.

Em novembro de 2012, o primeiro encontro realizado na Finlândia e Rússia discutiu o planejamento original e redefiniu a abordagem geral do projeto. Naquele momento decidiu-se pela abordagem às semelhanças e diferenças entre os BRICS, fazendo assim um distanciamento da suposta homogeneidade que o acrônimo denota. Além disso, o "Projeto BRICS" visa teorizar para além das tradições ocidentais dominantes e respeitar contextos históricos locais num cenário global. Assim, firmou-se o compromisso de analisar práticas jornalísticas num contexto informativo mais amplo considerando inclusive produções de entretenimento assim como a relação da mídia dita hegemônica com a evolução constante da Internet e novas mídias. Os dados empíricos seguirão as seguintes temáticas: sistemas

1 Para mais informações sobre os países BRICS, ver: http://www.brics5.co.za/.

2 Leia mais sobre o "Projeto BRICS" em: http://uta.fi/cmt/tutkimus/BRICS.html

3 O Laboratório de Estudos em Comunicação Comunitária (LECC) designa um grupo de professores e alunos de Graduação e Pós-Graduação da Escola de Comunicação da UFRJ, voltado para a experimentação pedagógica e a pesquisa da comunicação articulada aos modos de comunidade e de solidariedade que não se acham inteiramente abrangidos pelo que contemporaneamente se entende como sociedade. 
midiáticos (leis e regulamentação, perfil factual de produção e distribuição, economia política), mídia e jornalismo e educação de jornalistas. A pesquisa propõe uma análise crítica de dados coletados a partir de métodos quantitativos (ex. questionários) e qualitativos (ex. entrevistas semiestruturadas, revisão de literatura e documentos oficiais).

A questão da participação cidadã nos sistemas midiáticos também será abordada no "Projeto BRICS." O tema será analisado não só a partir das formas de participação da audiência nos meios massivos, mas também em plataformas midiáticas alternativas desenvolvidas por cidadãos. Neste caso, provavelmente as atividades mais reconhecidas internacionalmente são as rádios comunitárias. Surgidas na América Latina na década de 1940, as rádios comunitárias são exemplos de articulação e resistência cultural e política em diversos tipos de contextos sociais, culturais e políticos. A existência e a força institucional da Associação Mundial de Rádios Comunitárias (AMARC) ${ }^{4}$ comprovam a significância da apropriação de novas e antigas tecnologias da informação e comunicação (TICs) para a formação de plataformas e redes alternativas e locais de comunicação dentro de sistemas midiáticos em sua grande parte dominados por elites políticas e/ou econômicas. Porém, este panorama não garante que rádios comunitárias sejam vistas - e ouvidas - em todos os cantos do mundo.

Num levantamento inicial do "Projeto BRICS", a situação das rádios comunitárias indica o desafio a ser enfrentado durante a pesquisa. Entre outros itens, os representantes dos BRICS foram perguntados sobre a quantidade de emissoras de rádio (privadas, estatais e sem fins lucrativos) em seus países. Três dos cinco times locais indicaram a presença significativa de rádios comunitárias: Brasil (4.781 rádios comunitárias de $8.770^{5}$ no total), Índia (371 rádios comunitárias de 611) e África do Sul (165 rádios comunitárias de 201). Ao mesmo tempo, Rússia e China não apresentaram nenhuma menção às rádios comunitárias. Estes resultados preliminares trazem à tona uma questão imprescindível para o desenvolvimento da pesquisa comparativa de práticas comunitárias nos BRICS: devemos nos conformar com a aparente inexistência de casos a serem estudados em Rússia e China, ou devemos refletir nas bases conceituais que utilizamos para desenvolver estes tipos de análise?

4 Associação Mundial de Rádios Comunitárias - AMARC (http://amarc.org).

5 Entre emissoras comerciais, educativas e comunitárias, incluindo licenças definitivas e provisórias nas bandas de frequência FM, OM, OC e OT. Fonte: Página do Ministério das Comunicações (http://www.mc.gov.br/acoes-e-programas/radiodifusao/dados-gerais), acesso em 02.02.2013. 
A conformação com a aparente inexistência de rádios comunitárias na Rússia e China é problemática pois há o risco de descartar-se, de antemão, a observação e análise de formas de resistência política e cultural encampadas em diferentes plataformas midiáticas nestas sociedades. Com isso, casos como a formação de fóruns para debate e mobilização de cidadãos através de transmissões radiofônicas via Internet na China (ZHOU, 2012) e o uso de espaços em rádios comerciais livres para a circulação de informações e mobilização oposicional por atores da sociedade civil na Rússia (MATZA, 2009) passariam despercebidos. Logo, se atividades (mesmo que em número pequeno e pouco visível) de comunicação cidadã existem, como fazer para que elas não passem despercebidas? Como garantir que novas formas de ser do rádio - assim como outras formas de comunicação contra-hegemônica sejam levadas em conta?

Uma possível explicação está nos aportes conceituais e teóricos que usamos na condução destes estudos comparativos. Em estudos comparativos de sistemas midiáticos em geral, práticas de comunicação cidadã permanecem ignoradas. Hallin e Mancini (2004), por exemplo, concentram-se em um sistema midiático formado por empresas privadas e públicas de comunicação. Recentemente, os autores expandiram a análise para além do mundo ocidental (HALLIN \& MANCINI, 2012) num volume editado com autores do oriente e do hemisfério sul. Ainda assim, não há menção de práticas comunicacionais cidadãs - nem mesmo das estabelecidas rádios comunitárias - como parte dos sistemas midiáticos analisados.

Em outro estudo comparativo-normativo, Christians et al (2009) incluíram a questão de movimentos de mídias participativas no debate mais amplo sobre teorias normativas da mídia. Para estes autores, atividades como rádios comunitárias devem ser encorajadas (p. 60). Mas a ideia de encorajamento denota que estas ações devem ocorrer num sistema político regido por leis e regras estabelecidas. Isto gera uma orientação burocrática mesmo em estudos específicos de comunicação comunitária. Davis e Tachi (2002), por exemplo, comparam rádios comunitárias através de critérios usados pelos autores parcialmente burocráticos: definição de rádios comunitárias a partir de leis e regulamentações, licenciamento e alocação de frequências. Outros critérios foram basicamente descritivos: formas de financiamento e características de programação, audiência, equipe de produção e apoiadores. Estes critérios são, sem dúvida, válidos e formam uma estrutura razoável para análise comparativa. Porém, restringem a comunicação cidadã a casos legitimados a partir da legislação vigente. Assim, em relação aos BRICS, Rússia e China - países que apresentam um forte controle do Estado 
sobre a utilização das TICs - continuariam demonstrando uma aparente ausência de ações de comunicação cidadãs.

Como, então, desenvolver estudos comparativos de mídia de maneira a incluir rádios comunitárias e outras formas de comunicação cidadã como partes constitutivas, mesmo que com fissuras (RODRIGUEZ, 2001), dos sistemas midiáticos analisados? Uma maneira é utilizar conceitos que contribuam não só para facilitar a localização destas ações em contextos sociopoliticos distintos, mas também que contribuam para analisar os valores sociais e políticos que estas ações representam para as pessoas envolvidas em suas produções e recepções. Neste sentido, um conceito que pode facilitar este tipo de comparação mais aprofundada, feita a partir de um viés mais éticopolítico do que burocrático é o conceito de mídia comunitária sob a perspectiva da comunidade gerativa (PAIVA, 2000 e 2004) e comunidade de afeto (PAIVA, 2012).

\section{A 'COMUNIDADE GERATIVA' E O AFETO COMO NORTEADORES DA ANÁlISE DAS MÍdIAS COMUNITÁRIAS}

A reinterpretação do conceito de comunidade gerativa tem sido uma experiência que surgiu no LECC nos últimos anos e alertou-nos para o caráter operativo que o conceito possibilita em oposição a uma ideia de "comunidade negativa", imaginada por uma linhagem de autores ao longo da história do conceito de comunidade (ex.: BAUMAN, 2003). Isto porque, ao ressurgimento de grupos e facções portadoras da marca da "comunidade negativa", onde a ritualização do ser em comum funda-se em práticas violentas de exclusão visceral de um outro alheio ao núcleo grupal, pretendia-se contrapor projetos sociais inclusivos e transformadores, reivindicativos da ideia de "comunidade gerativa". Ou seja, aquela experiência capaz de tirar sujeitos do torpor e inseri-los em práticas capazes de fazer frente ao esfacelamento do social. Por "comunidade gerativa" entende-se a vinculação entre sujeitos cujo propósito maior é efetivamente seu florescimento organizativo em harmonia com o contexto histórico e social de seu tempo.

Assim, propôs-se que, apesar de a forma social estar marcada pela violência ou repressão, os grupos minoritários e oposicionistas podem optar por ações sociopolíticas inclusivas que priorizem a coexistência harmônica entre cidadãos. Isto porque, apesar do reconhecimento da existência de vários esquemas minoritários vigorando na nova ordem 
mundial que podem intervir e realizar mudanças radicais na ordem hegemônica, é necessária a ação de estruturas mais sólidas que as atuais ações midiáticas de "minorias flutuantes".

Pode-se conceber a existência de uma alternativa que se apresenta como projeto político, ecológico, existencialista - no entendimento da conviviabilidade necessária entre os povos - e também como projeto de vinculação identitária e educacional. "Comunidade gerativa" designa o conjunto de ações (norteadas pelo propósito do bem comum) que podem ser executadas por um grupo e/ou conjunto de cidadãos. A proposição parte da evidência de que o horizonte que caracteriza a sociedade contemporânea - a falência da "política de projetos", a forte tônica individualista e cosmopolita, além da excessiva presença da violência nas relações sociais - acaba por impulsionar a busca de alternativas.

Dentre as alternativas, situa-se a atuação de uma política gerativa com ênfase nas ações práticas do quotidiano e da localidade. O modelo neoliberal produziu um Estado mínimo (no caso dos BRICS, mais observável no Brasil, na Índia e na África do Sul), progressivamente incapaz de atuar no entendido âmbito de suas intransferíveis atuações, como a saúde, a educação, a habitação, a segurança, etc. Mas tal perspectiva não se define apenas como localista - de sentido exclusivista e ultranacionalista - pois é necessária a atuação no ambiente multicultural e de trocas comunicacionais que definem a atualidade.

A comunidade gerativa propõe-se a agir em resposta ao atomismo social, à política centrada no mercado e ao predomínio de um Estado gerencial e burocrático. Já se esboçava uma reinterpretação do conceito tradicional de comunidade formulado por Ferdinand Tönnies (1979), resgatando facetas como a vinculação social e a preocupação territorial, que engendram a preocupação com o patrimônio cultural. Já estavam presentes nessa proposta aspectos da sociabilidade que parecem ter perdido sentido e que passam a ser o enfoque central, como cooperação, solidariedade, tolerância, fraternidade, docilidade, amizade, cooperação e generosidade.

Aos grupos minoritários, como devir - a partir da ideia de fluxo de mudança que permeia um grupo (DELEUZE \& GUATTARI, 1997) - cabe o papel de portadores dessas novas proposições de defesa do social. Pensa-se numa estrutura social capaz de abarcar a multiplicidade e a convivialidade que nos fazem repensar cidadania não como um status adquirido com a maioridade, mas como processo de engajamento em questões e disputas sociais a partir da interação com outros indivíduos. Provavelmente a cidadania é um dos principais conceitos a serem reinterperpretados por esta nova disposição. Um conceito a ser conjugado com outras necessárias reinterpretações. Dentre os conceitos a serem evocados 
para este trabalho de envergadura prático-teórica capaz de promover reformulações na estrutura social estão: convivialidade, diferença/igualdade, inclusão, compartilhamento, pertencimento, diálogo, comunicação.

No esforço por definir o papel social dos grupos minoritários, é preciso lembrar que a mera atuação nas brechas abandonadas pelas instituições não bastaria para recuperar o tecido social. Não basta apenas oferecer iniciativas onde o poder público simplesmente deixou de atuar. A ação neste vazio é premente e fundamental. Mas, é preciso que ela se faça transitiva e, para tanto, a espiral em torno da ideia do "gerativo" é imperiosa.

Não se trata de resgate. Esta noção supõe um retorno temporal impossível especialmente por ser pouco operativo e inevitavelmente saudosista. Trata-se, sim, da criação de novas estruturas sociais capazes de comportar a complexidade da contemporaneidade e de seus sujeitos, acorrentados a antigos e ineficazes dogmas e conceitos. Não é viável o retorno às mediações tradicionais, como também não é possível desconhecer o universo da midiatização, ou seja, a impregnação de todas as antigas mediações pelos artefatos próprios da mídia.

Se por um lado o conceito de comunidade gerativa tem uma conformação operativa, a compreensão da questão do sensível como amálgama social configurou a necessidade de investigação em torno da perspectiva da comunidade do afeto. O ponto de partida para esta conceituação foram as ideias do filósofo italiano Gianni Vattimo (2002) sobre a comunicação, que ele pressupõe ser uma comunidade afetiva, mantida por um acordo de gostos em torno do problema da partilha coletiva de vozes e sensações. Para ele:

Se a situação afetiva é algo que encontramos sem dela podermos dar razão, a conclusão será que ela nos põe perante o fato de o nosso modo originário de captar e compreender o mundo ser algo cujos fundamentos nos escapam, sem ser, por outro lado, uma característica transcendental de uma razão 'pura', já que a afetividade é precisamente o que cada um de nós tem de mais profundo, de mais individual e de mais cambiante." (VATTIMO, 1971, p. 39).

O mesmo pensamento norteou as bases do pensamento do filósofo francês Jacques Ranciere (2005), que encontrou no partilhamento da profusão imagética um enfeixamento teórico capaz de explicar a vida e o mundo atual. Por esta trilha, a partir da investigação da vinculação afetiva se compreende uma vetorização da relação entre os indivíduos movidos muito mais por esta determinante que pelos tradicionais laços de parentesco, territoriais e até mesmo legais. O lugar da comunicação desponta um enfoque fundamental nesse processo, 
como ajustadamente marcou Muniz Sodré (2006) em sua preocupação com a real natureza do sensível nos processos comunicacionais. Em outro momento, Muniz Sodré (SODRÉ, 2002) faz uma análise epistemológica da comunicação e propõe que seu núcleo teórico seja a vinculação, entendida como "a radicalidade da diferenciação e aproximação entre os seres humanos" seja sob "a forma da luta social por hegemonia política e econômica, seja sob a forma do empenho ético de reequilibração das tensões comunitárias.” (2002, p. 223). É na vinculação que se situa o centro gerador do entendimento de comunidade e comunicação em Sodré, cuja proposta se avizinha e alimenta nossa proposta teórico-metodológica.

É a comunicação como aparato e geradora da ordem do sensível o lugar mais adequado para conceber esse estado de "re-volta" (KRISTEVA, 2012, p. 18). A comunicação comunitária insere-se definitivamente como ator principal deste panorama. E por sua história e importância social e política, as rádios comunitárias brasileiras constituem o nosso primeiro enfoque. Porém, este enfoque se insere na busca por um modelo analítico que inclua também outras formas de comunicação comunitária - práticas comunicacionais contra-hegemônicas em contextos sociopolíticos distintos - de modo a dar conta do desafio de realizar um estudo comparativo de mídia nos BRICS.

\section{A INCAPACIDADE DO FORMALISMO PARA LIDAR COM A DIVERSIDADE DAS RÁDIOS COMUNITÁRIAS BRASILEIRAS}

Se aplicássemos para as rádios comunitárias brasileiras um dos critérios utilizados pelos supracitados autores Davis e Tachi (2002), em seu estudo comparativo, estaríamos em maus lençóis. É que os autores adotam o critério burocrático da legalidade e, no Brasil, a lei restritiva, a repressão estatal, o excesso de burocracia e ineficiência na liberação de outorgas têm levado diversas emissoras para a ilegalidade, ficando, assim, invisíveis para a aferição dos autores.

O Estado entende como rádio comunitária somente emissoras com outorga e cuja operação se enquadrem na Lei 9.612/98, que regulamenta a radiodifusão comunitária brasileira. A definição legal, logo em seu primeiro artigo, estabelece que rádio comunitária é aquela "operada em baixa potência e cobertura restrita" e circunscrita "ao atendimento de determinada comunidade de um bairro e/ou vila" (BRASIL, 1998a). Além disso, a Lei reserva "um único e específico canal na faixa de frequência do serviço de radiodifusão sonora em frequência modulada" (art. $5^{\circ}$ ), veda a formação de redes (art. 16 $6^{\circ}$ e estabelece que as 
comunitárias "operarão sem direito a proteção contra eventuais interferências" causadas por demais emissoras $\left(\operatorname{art} .22^{\circ}\right.$ ). Além disso, o regulamento da Lei estabelece potência máxima de 25 watts $\left(\operatorname{art} .5^{\circ}\right)$ e permite como forma de sustentabilidade somente o apoio cultural $\left(\operatorname{art} .32^{\circ}\right)$, impedindo qualquer publicidade (BRASIL, 1998b). Apesar de escapar do escopo deste artigo, cabe colocar que todos os pontos aqui destacados têm sido alvo de críticas por dificultar - e, em muitos casos, inviabilizar - o pleno usufruto da radiodifusão pelas comunidades (MALERBA, 2009). Inclusive, recentemente, no Seminário "Uma nova lei para as rádios comunitárias" realizado pela AMARC Brasil, no dia 21 de novembro de 2012, em Brasília, diante das críticas à Lei, o próprio representante do Ministério das Comunicações no evento, Octávio Pieranti, reconheceu que a legislação não responde à realidade das rádios. Em sua fala, porém, destacou como avanço o Plano de Outorgas que, desde 2011, tem expedido avisos de habilitação para novas rádios em 1.856 municípios, ponderando que, nas últimas duas chamadas, cerca de $70 \%$ das localidades não fizeram solicitações, o que, para ele, poderia indicar que não haja interesse por outorgas. O que para Pieranti é um indício de uma pretensa universalização do acesso ao serviço teve como resposta de um dos radialistas comunitários presentes, Claudecir Zilio, da Rádio Metropolitana FM, de Juína, no Mato Grosso, a interpretação de que a baixa procura se deve precisamente a má legislação: "hoje é mais fácil uma emissora se manter na ilegalidade” (PULSAR BRASIL, 2012a).

A ilegalidade marca a história dessas rádios. Em outro momento (MALERBA, 2006), fizemos um breve panorama histórico dessas emissoras, mas cabe-nos dizer que a multiplicação das rádios comunitárias, no início da década de 1980, coincidiu com o processo de reabertura democrática, sendo, ao mesmo tempo, consequência e instrumento da então recente rearticulação da sociedade civil por transformações políticas e sociais. Porém, sem um marco que validasse sua existência, essas rádios eram alvo de intensa e sistemática repressão estatal. A longa brecha legal acarretou um problemático estigma de ilegal ("pirata"), que até hoje resiste quando o assunto é rádio comunitária. A chegada da lei não mudou esse panorama: após 15 anos da Lei 9.612, as rádios continuam sendo perseguidas pelo Estado brasileiro. Segundo dados da Agência Nacional de Telecomunicações (Anatel), em 2010, foram interrompidas 940 rádios sem outorga, uma média de mais de 2,5 emissoras fechadas por dia. No ano seguinte, foram mais 698 fechamentos ou quase duas rádios por dia na mira da Polícia Federal e da Anatel $^{6}$. Um caso emblemático é o da Rádio Alternativa FM,

6 Dados obtidos a partir de uma solicitação da ONG Artigo 19 baseada na recentemente aprovada Lei de Acesso à Informação. Detalhamentos em http://artigo19.org/centro/esferas/detail/251, acesso em 03.02.2013. 
localizada na cidade satélite de Planaltina, no Distrito Federal, cujos números impressionam: em seus 14 anos de funcionamento, foram 12 fechamentos com apreensão completa dos equipamentos e oito inquéritos policiais; seu diretor, o radialista Julimar Gonçalves de Carvalho, foi processado na Justiça Federal seis vezes e condenado cinco (PULSAR BRASIL, 2013). E mesmo as outorgadas continuam sob ataque do Estado: de acordo com um recente balanço de 2012, o Ministério das Comunicações aplicou 741 sanções a emissoras de rádio e TV: dessas, a maioria (377 ou 50,8\% do total de casos) teve como alvo as rádios comunitárias (MARINONI, 2013).

A eficácia do Estado em reprimir não coincide com sua rapidez em conceder outorgas para rádios comunitárias. Apesar de recentemente anunciar uma reestruturação do setor ${ }^{7}$, o Ministério das Comunicações pode demorar anos para analisar um pedido. Outro caso emblemático é o da Rádio Comunitária Coité FM, de Conceição do Coité (BA), associada da AMARC Brasil e que encampa diversas ações cidadãs em sua comunidade, como o projeto Pelas Ondas do Rádio, oficinas de comunicação com crianças carentes do bairro periférico da Mansão (CRIAR BRASIL, 2012). O pedido de outorga foi feito no ano de criação da lei para o setor e, após 15 anos, a licença da emissora ainda não foi liberada. Com isso, a Coité FM já foi fechada três vezes e o seu diretor (que prefere não ser identificado) responde judicialmente por crime federal.

Tendo em vista esse cenário, nos parece ineficiente o critério da legalidade para lidar com o mapeamento das rádios comunitárias brasileiras: como a Coité, são inúmeros os casos de rádios que são comunitárias, mas não têm outorga. E vice-versa - para acrescentar mais um fator de complexidade ao tema -, pois já é recorrente a denúncia de que diversas entidades com intuitos meramente político-partidários e/ou comerciais têm ocupado o já exíguo espaço legal reservado para as comunitárias. É o que atesta a professora Márcia Vidal Nunes numa pesquisa com cerca de quatrocentas rádios comunitárias outorgadas no estado do Ceará:

apesar das exigências legais, a maior parte das emissoras que se dizem comunitárias, na verdade, não o são. Muitas associações fantasmas foram criadas por políticos, arregimentando a participação popular graças às práticas clientelistas, que envolvem uma indiscriminada troca de favores. No Ceará, das cerca de quatrocentas emissoras existentes, apenas $10 \%$ são autenticamente comunitárias, ou seja, têm gestão coletiva, programação

7 Disponível em http://www.mc.gov.br/radio-e-tv/noticias-radio-e-tv/23212-minicom-propoe-plano-ineditode-outorgas-para-radios-comunitarias. Acesso em 03.02.2013. 
plural e participação popular efetiva em todas as instâncias da emissora. (NUNES, 2001, p. 242)

O uso das rádios comunitárias como barganha política foi identificado na pesquisa realizada com todas as outorgas expedidas de 1998 a 2004, pelos pesquisadores Venício Lima e Cristiano Aguiar Lopes: das 2.205 rádios pesquisadas, foi possível identificar vínculos políticos em 1.106, ou seja, 50,2\%. E as conclusões da pesquisa vão além: isso se deve ao próprio esquema de concessão de outorgas. Os processos politicamente apadrinhados têm 4,41 vezes mais chances de receberem a outorga que os demais. Há uma extensa lista de exigências determinadas por lei e, para cumpri-las, um padrinho político torna-se essencial. Os deputados contam com a assessoria de seus gabinetes, que trabalham, muitas vezes, como despachantes dos processos de pedido de outorga, sanando documentação pendente e até apresentando essa documentação ao Ministério das Comunicações. (LIMA e LOPES, 2007).

Outro grupo inicialmente estranho aos auspícios da radiodifusão comunitária também tem sido recorrente nas outorgas: as entidades religiosas. Apesar de a regulamentação da Lei vetar qualquer tipo de proselitismo (BRASIL, 1998a, art. 30), como destaca Peruzzo, é comum "emissoras pertencentes a igrejas, principalmente evangélicas, que desfiguram o sentido comunitário por meio do proselitismo religioso que praticam" (2010, p. 6). Na citada pesquisa de Lima e Lopes, do total das 2.205 emissoras comunitárias outorgadas analisadas, 120 possuíam vínculos religiosos, ou seja, 5,4\%. De qualquer forma, Peruzzo pondera que, mesmo com programação majoritariamente religiosa, "há rádios que prestam serviços de interesse público benéfico em suas localidades” (2010, p.5) e são usadas para conscientização e promoção social. É o que conclui Volpato (2010) em sua análise comparativa entre a emissora dita comunitária Rádio Gospel FM, de Marília (SP) e a legalmente comunitária Rádio Jornal FM, de Pirajuí (SP). Apesar de ligada a Igreja Evangélica das Nações e

mesmo sem primar pela pluralidade de opiniões e ideias no que tange a diversidade religiosa, [a Rádio Gospel FM] aproxima-se mais do comunitário do que a outra emissora estudada, seja pela viabilização da participação popular, seja pelas ações sociais, seja pelos processos educativos e de cidadania promovidos (VOLPATO, 2010, p. 14)

Além disso, é importante destacar que as rádios comunitárias brasileiras estão passando por mudanças recentes, resultantes das apropriações que fazem das novas tecnologias de informação e comunicação. A partir de uma pesquisa (MALERBA 2009), verificamos que as mutações tecnológicas têm propiciado a essas mídias a ampliação de suas ações em uma 
promissora atuação em rede, aumentando sua visibilidade e incidência política. Através da hibridização dos meios, da renovação da linguagem e de novas formas de vinculação, seus modos de agir acompanham tais mudanças, tornando-se cada vez mais complexos e intrincados. Essa apropriação das ferramentas tecnológicas exige a revisão das terminologias, abordagens e modelos para dar conta das novas possibilidades inauguradas para as iniciativas midiáticas comunitárias: elas passam a agir de forma cada vez mais desterritorializada e articulada com outros atores sociais, e vão alterando seus perfis e escopos inicias de ação. $\mathrm{Na}$ verdade, essas emissoras acompanham a própria evolução recente do rádio, que extrapolou as ondas hertzianas:

a radiodifusão sonora não é mais, apenas, singular, havendo que insistir em uma concepção plural (...) [Hoje], o veículo também se amalgama à (...) internet, onde aparece com a rede mundial de computadores ora substituindo a função das antigas emissões em OC [ondas curtas], ora oferecendo oportunidade para o surgimento das chamadas webrádios ou, até mesmo, servindo de suporte a alternativas sonoras assincrônicas como o podcasting", (FERRARETO, 2007, p. 547).

Um exemplo são as webrádios comunitárias, do qual podemos citar a Rádio Comunitária Santa Marta. Desde o seu início em 2010, a Rádio Santa Marta usou o rádio convencional e a Internet para fazer suas transmissões. Depois do fechamento e da apreensão de seus equipamentos no dia 3 de maio de 2011, os participantes da rádio - todos moradores da comunidade do Santa Marta - decidiram continuar com a rádio somente na internet ${ }^{8}$ enquanto esperam o resultado do pedido de outorga junto ao Ministério das Comunicações. A dualidade nas plataformas da transmissão da Rádio Santa Marta tem gerado uma dinâmica interessante se olharmos sob a perspectiva da comunidade de afeto e das possibilidades extraterritoriais de gerativismo comunitário. Por um lado, após a decisão de manter as transmissões somente online, a participação da maior parte dos comunicadores da rádio se esvaiu. Houve perda de interesse em manter os programas sob a justificativa de que a audiência ideal - os moradores do morro - não teriam o hábito de usar Internet. Por outro lado, as transmissões online tem colaborado para a aproximação de atores externos e o desenvolvimento de novas redes de articulação, mobilização e ação com os atores locais da comunidade do Santa Marta (CUSTÓDIO, 2011).

8 http://www.radiosantamarta.com.br/transmissao 
Além disso, seguindo a proposta de Ferrareto quanto às novas formas do rádio, não seria o caso de incluirmos no escopo do rádio comunitário os incontáveis podcasts ${ }^{9}$ de caráter contra-hegemônico encontrados na rede? Num outro trabalho (MALERBA, 2009), analisamos o Radiotube (www.radiotube.org.br), uma rede social de compartilhamento de material informativo - principalmente em áudio, os podcasts - exclusivamente ligado à cidadania, que congrega via internet milhares de ativistas, estudantes, integrantes de rádios comunitárias, professores, entre outros de diferentes partes do Brasil e do mundo falante de Português.

Essa multiplicidade de modos de ser e de agir da - ampliada - comunicação comunitária exige que abandonemos fórmulas fáceis - e imprecisas - para seu mapeamento. No caso específico das rádios comunitárias brasileiras, devemos voltar nossa atenção analítica para as particularidades do contexto político e sociocultural da comunidade em que ela surge. É preciso levar em conta que as demandas - e os perfis - das emissoras variam de acordo com a conjuntura social específica, além de estarem sujeita às pressões conflitivas impostas pela diversidade. Retomando nossa proposta, precisaremos, em cada rádio - ou em qualquer iniciativa midiática contra-hegemônica - analisar se há e qual é a intensidade do vínculo comunitário aí existente. Talvez uma forma de medir o quão vinculativa, o quão gerativa é uma iniciativa comunitária seja analisarmos as práticas solidárias, cidadãs e políticas em que estão engendradas essas rádios: pois é como consequência da ação conjunta que brota o afeto, esse sempre amálgama de qualquer comunidade. Trata-se de analisar se as propostas de tais iniciativas trazem valores como cooperação, solidariedade, tolerância, fraternidade, docilidade, amizade, cooperação e generosidade. Na supracitada necessidade de reinventar o conceito de cidadania, teríamos que lidar com essa abrangência.

Sabemos do desafio que estamos propondo: exigirá a análise caso a caso e a busca de indicadores plausíveis - sob o risco de cairmos em perigosas abstrações e relativizações para medir o que é aparentemente imensurável: como se mede o vínculo? qual a medida para o afeto? qual o limite da solidariedade? - são perguntas que exigirão um grande esforço metodológico. Mas talvez o caminho mais longo seja o único possível em se tratando de iniciativas calcadas na - também imensurável - revolta que motiva as iniciativas contra-

9 Podcast: modalidade assincrônica de radiodifusão sob demanda, cujo nome resulta da junção da expressão plublic on demand + casting. Trata-se de programas radiofônicos, de diferentes gêneros (jornalísticos, artísticos, musicais, científicos etc.), normalmente gravados em formato .mp3 para serem facilmente baixados da internet e escutados em $m p 3$ players, celulares ou mesmo no computador. O podcasting democratizou anda mais o acesso ao rádio via Internet, tornando cada ouvinte um potencial emissor de conteúdos digitais. 
hegemônicas. Um primeiro e necessário passo é esse de identificar o problema e saber aonde se quer chegar; o próximo será nos debruçarmos sobre casos reais, em contextos sociais, políticos e culturais diversos, de modo a catar semelhanças e diferenças comuns, capazes de nos dar pistas dos indicadores mais adequados à nossa problemática. Por isso a relevância de pesquisarmos e compararmos iniciativas contra-hegemônicas em países tão diversos como os que compõem os BRICS. Certamente mais estudos de caso e esforços comparativos ainda se fazem necessários (o "Projeto BRICS" oferece oportunidade única neste sentido). Mas este trabalho é evidência da potencialidade destes conceitos para viabilizar comparações mais amplas e aprofundadas das práticas, características e, sobretudo, das motivações de cidadãos para se utilizar do rádio e de outras TICs em suas lutas por justiça social, liberdade e pelo exercício pleno da cidadania.

\section{REFERÊNCIAS}

BAUMAN, Z. Comunidade: a busca por segurança no mundo atual. Rio de Janeiro: Jorge Zahar, 2003.

BRASIL, Lei 9.612, de 1998, que institui o Serviço de Radiodifusão Comunitária e dá outras providências (1998a); Decreto 2.615, de 1998, que aprova o Regulamento do Serviço de Radiodifusão Comunitária (1998b).

CHRISTIANS, C.G; GLASSER, T.L; MCQUAIL, D; NORDENSTRENG, K. \& WHITE, R. Normative theories of the media: journalism in democratic societies. Illinois: University of Illinois Press. 2009.

CRIAR BRASIL. Criar para todas as vezes - boletim informativo mensal do Centro de Imprensa, Assessoria e Rádio - Criar Brasil. Ano 5, nº 51, agosto de 2012. Disponível em http://www.criarbrasil.org.br/uploads/boletins/ChamadaBoletimCriarParaTodas VozesAgosto 2012.pdf. Acesso em 13.2.2013.

CUSTÓDIO, L. They still matter! The importance of print and analogue media for youth civic participation in the digital age. Trabalho apresentado à Seção de pesquisa em 
comunicação participativa da conferência da Associação Internacional de Pesquisa em Mídia e Comunicação (IAMCR), Istambul (Turquia), de 13 à 17 de Julho de 2011.

DAVIES, E.P. \& TACHI, J.O. Community radio in global context: a comparative analysis in six countries. Londres: Thames Valley University. 2002.

DELEUZE, G. \& GUATTARI, F. Mil platôs. Rio de Janeiro: Editora 34, 1997.

FERRARETTO, L. A. Alterações no modelo comunicacional radiofônico. In. $\mathrm{e}$

Klöckner, L. (org.) E o rádio? Novos horizontes midiáticos (online). 2007.

HALLIN, D \& MANCINI, P. Comparing media systems: three models of media and politics. Nova York: Cambridge University Press. 2004.

HALLIN, D. \& MANCINI, P. Comparing media systems beyond the Western world. Nova York: Cambridge University Press. 2012.

KRISTEVA, J. L'avenir d'une revolte. Paris: Flammarion, 2012.

LIMA, V. A. de; LOPES, C. A. Rádios Comunitárias: Coronelismo Eletrônico de novo tipo. Observatório da Imprensa (online), São Paulo: n. 439, 26 jun. 2007.

MALERBA, J. P. C. Rádios comunitárias 2.0: propostas éticopolíticas de uma rede de redes. Dissertação (Mestrado) - Escola de Comunicação/ UFRJ, 2009.

Rádios Comunitárias: ampliando o poder de ação. 2006, $2^{\circ}$ semestre. Monografia (Habilitação em Jornalismo) - ECO/UFRJ. Disponível em www.overmundo.com.br/banco/radios-comunitarias-ampliando-o-poder-de-acao.

MARINONI, B. Observatório do direito à comunicação. Ministério das Comunicações aplica 741 sanções a emissoras em 2012, 29 de janeiro de 2013. Disponível em http://www.direitoacomunicacao.org.br/content.php?option=com_content\&task=view\&id=95 96. Acesso em 13.2.2013.

MATZA, T. Moscow's Echo: technologies of the self, publics and politics on the Russian talk show, Cultural Anthropology, 24(3), 2009. 
NUNES, M. V. Rádios comunitárias no século XXI: exercício da cidadania ou instrumentalização da participação popular?. In: BIANCO, N; MOREIRA, S. V. (orgs). Desafios do rádio no século XXI. São Paulo: INTERCOM, Rio de Janeiro: UERJ, 2001. PAIVA, R. Comunidade Gerativa. In: V Congresso Latinoamericano de Ciencias de la Comunicación, Santiago. V ALAIC, 2000.

PAIVA, R. Estratégias de Comunicação e Comunidade Gerativa. In: Cicilia M Krohling Peruzzo. (Org.). VOZES CIDADÃS. 1ed. São Paulo: Angellara, 2004, p. 57-74

PAIVA, Raquel. A Comunidade do afeto. Revista Matrizes, São Paulo, ECA/USP, v. 6, p. 63-75, 2012.

PERUZZO, C. M. K. Rádios Comunitárias no Brasil: da desobediência civil e particularidades às propostas aprovadas na CONFECOM. Trabalho apresentado ao GT Economia Política e Políticas de Comunicação, Encontro Anual da Compós realizado na PUC-Rio de 8 a 11 de junho de 2010.

PULSAR BRASIL, Rádio Alternativa FM enfrenta problemas para funcionar após legalização, 7 de fevereiro de 2013. Disponível em http://amarcbrasil.org/radio-alternativa-

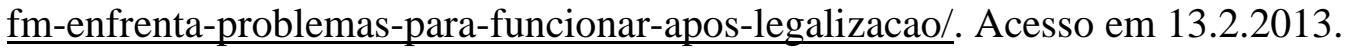

Lei restritiva pode causar desinteresse pela legalização de comunitárias, 22 de novembro de 2012. Disponível em http://www.brasil.agenciapulsar.org/nota.php?id=9341. Acesso em 13.2.2013.

RANCIERE, J. A partilha do sensível. São Paulo, Editora 34. 2005.

RODRIGUEZ, C. Fissures on the mediascape: an international study of citizens' media. Cresskill (NJ): Hampton Press. 2001.

SODRÉ, M. Antropológica do espelho. Petrópolis: Vozes, 2002.

SODRÉ, M. As Estratégias Sensíveis - Afeto, Mídia e Política. Petrópolis: Vozes, 2006.

TÖNNIES, F. Comunidad y Asociación - el comunismo y el socialismo como formas de vida social. Barcelona, Ed. Península, 1979.

VATTIMO, G. Introdução a Heidegger. Edições 70, 1971. 
Comunicação e Transparência. Palestra proferida na abertura da XI Compós, Rio de Janeiro, 2002.

\section{VOLPATO, M. O. A religião nas rádios comunitárias “Gospel FM” e “Jornal FM". In}

Revista Alterjor do Grupo de Estudos Alterjor: Jornalismo Popular e Alternativo (ECA-USP), Ano 1, Volume 1, Edição 1, Janeiro-Dezembro de 2010.

ZHOU, XIAN. The challenging landscape of political communications in China em Holli A. Semetko and Margaret Scammell (Eds) The SAGE handbook of political communication, Londres: SAGE. 2012.

Original recebido em: 30/08/2013

Aceito para publicação em: Novembro de 2013

Raquel Paiva

Professora Associada IV, Pesquisadora $1^{a}$ CNPq, Escola de Comunicação/UFRJ

João Paulo Malerba

Doutorando e mestre em Comunicação e Cultura pelo Programa de Pósgraduação da Escola de Comunicação/UFRJ; atual coordenador executivo da Associação Mundial de Rádios Comunitárias - AMARC Brasil.

Leonardo Custódio

Mestre em Ciências Sociais e doutorando em comunicação pela Universidade de Tampere, Finlândia. Membro do Programa Finlandês de Doutorado em

Comunicação (2012-2015). 
